\title{
VIVIENDA DIGNA Y ZONAS DE ALTO RIESGO. MANDATOS COMUNES QUE CONFLUYEN EN LAACCIÓN DE TUTELA”
}

\author{
Mario Pedro Ríos Padilla
}

Recibido: Enero 30 de 2014

Aprobado: Marzo 19 de 2014

\section{RESUMEN}

Este documento es un avance de investigación del proyecto de investigación titulado "El Derecho a la Vivienda Digna y las Acciones Constitucionales en Colombia: desarrollo en la jurisprudencia y doctrina constitucional desde 1991", en el que se hace una evaluación de las intervenciones que ha desplegado la Corte Constitucional, a instancias de procesos iniciados por acciones de tutela, para la satisfacción del derecho a la vivienda digna de habitantes (damnificados) de zonas de alto riesgo, por la ineficacia del procedimiento administrativo previsto para ello.

Palabras Claves: Derechos sociales, hermenéutica constitucional, acción de tutela.

\footnotetext{
* Artículo avance del proyecto de investigación titulado "El Derecho a la Vivienda Digna y las Acciones Constitucionales en Colombia: Desarrollo en la Jurisprudencia y Doctrina Constitucional (1991-2011)" desarrollado por el Semillero de Investigación en Hermenéutica Jurídica -HERMES- adscrito al Grupo de Investigación en Hermenéutica Jurídica del Centro de Investigaciones Socio-Jurídicas "Laureano Gómez Serrano" de la Universidad Autónoma de Bucaramanga. En esta investigación participaron los egresados Carlos Arturo Duarte Martínez y Carlos Mario Frías Rubio. Actualmente participan en ella los estudiantes Andrés Felipe Parra Rivera y Leonardo Acosta Arengas.

** Estudiante de VIII Semestre de Derecho de la Universidad Autónoma de Bucaramanga. Miembro del Semillero de Investigación en Hermenéutica Jurídica-HERMES-. Por este ensayo su autor fue distinguido con una Mención de Investigación dentro de la $11^{\mathrm{a}}$ Edición del Concurso de Investigación Formativa “Octavio Arizmendi Posada”2012-2013 (Ensayo Jurídico). Correo electrónico: mrios8@unab.edu.co
} 


\title{
DESCENT HOUSING AND HIGH RISK AREAS. COMMON MANDATES THAT CONVERGE IN A LEGAL ACTION FOR THE PROTECTION OF FUNDAMENTAL RIGHTS
}

\begin{abstract}
This document is the product of a research called "El Derecho a la Vivienda Digna y las Acciones Constitucionales en Colombia: desarrollo en la jurisprudencia y doctrina constitucional desde 1991" which provides an assessment of the interventions made by the constitutional court requested by lawsuits concerning the effectiveness and efficiency of the administrative procedure in the access to decent housing for residents of high risk areas.
\end{abstract}

Key words: Social rights, constitutional interpretation, a legal action for the protection of fundamental rights.

\section{HABITAÇÃO DECENTE E ÁREAS DE ALTO RISCO. MANDATOS COMÚNS QUE CONFLUIM NA AÇÃO DE TUTELA}

\section{RESUMO}

Este documento é um progresso do projeto de pesquisa intitulado "O Direito à Moradia Adequada e Ações Constitucionais na Colômbia: o desenvolvimento na jurisprudência constitucional e doutrina desde 1991" de pesquisa, em que uma avaliação das intervenções faz implantou o Tribunal Constitucional, após consulta iniciadas ações de proteção para garantir a eficácia e eficiência do procedimento administrativo para acesso a pessoas decentes de habitação (vítimas) de áreas de processos de alto risco.

Palavras chaves: Social, hermenêutica constitucional, tutela.

\section{INTRODUCCIÓN}

La lucha por el reconocimiento de los derechos no culmina hasta que se cuenta con mecanismos judiciales para exigir su cumplimiento. La 
apuesta por un ser imparcial, esto es, ajeno a los intereses de las partes en conflicto, que dé solución objetivamente a los problemas de la vida social, protegiendo los derechos fundamentales aun sobre la voz y el poder de la mayoría, es un elemento característico del Estado constitucional. Razón tiene Ferrajoli (2005) cuando señala que "el desarrollo del Estado de derecho es paralelo a la evolución de la jurisdicción”(p. 87).

La justiciabilidad de los derechos marca un antes y un después entre el Estado legislativo y el Estado constitucional: en el primero el derecho está supeditado a la Ley y a la política, lo decidido en el parlamento prevalece. En el Estado constitucional teniendo a la dignidad como paradigma y eje fundador, los extremos de las relaciones se invierten. El poder ahora se halla supeditado a los principios constitucionales. Las actuaciones llevadas a cabo en su ejercicio sólo son válidas si se corresponden con aquellos. La dignidad humana es la medida del poder, y la jurisdicción constitucional garantiza milimétricamente que sea así.

Uno de los puntos de mayor reticencia y oposición a este paradigma se manifiesta con los derechos sociales pues frente a ellos -dice el profesor de Camerino-que "se expande el papel de la jurisdicción" (Ferrajoli, 2005, p. 95). A falta de herramientas jurisdiccionales específicas de exigibilidad. Se apreciaría que la Constitución Política colombiana de 1991 contara para ellos con un equivalente a la acción de tutela y acción popular, que protegen y garantizan la observancia de derechos fundamentales y colectivos, respectivamente. Esa orfandad, sin embargo, no se puede traducir en una excepción a la garantía jurisdiccional de la Constitución, sino que por el contrario aumenta las cargas del Juez constitucional de adecuar herramientas para que la dejación de los deberes por quienes detentan el poder público no afecte la eficacia de los derechos sociales. La jurisdicción constitucional debe convertirse, de ser necesario, en el escenario en donde se evalúe la inacción de los poderes públicos frente a la exigencia de las prestaciones necesarias para su satisfacción.

La Corte Constitucional no ha eludido esta necesidad, y ha brindado herramientas a las personas para exigir el respeto de los derechos sociales. En sus poco más de 20 años de existencia, son múltiples las decisiones en que por vía de acción de tutela ha proferido órdenes precisas, frente a-especialmente- omisiones de las autoridades públicas 
que desconocen el derecho de -generalmente- sujetos de especial protección constitucional.

Auscultar en las sentencias, es pues, una labor que se debe emprender especialmente, para establecer las condiciones fácticas de exigencia, así como de las obligaciones precisas para la satisfacción de los derechos sociales, que muchas veces se pierden o esconden en la vasta actividad judicial del Tribunal Constitucional. Hacer frente a esta situación, es el principal objetivo del proyecto "El Derecho a la Vivienda Digna y las Acciones Constitucionales en Colombia: Desarrollo en la Jurisprudencia y Doctrina Constitucional (1991-2011)".

El objeto del escrito que se presenta se circunscribe en examinar las decisiones de la Corte Constitucional, frente a la afectación al derecho a la vivienda digna, a causa de la ubicación de edificaciones en zonas de alto riesgo. La importancia de este tema pasa, en primer momento, en que casos como los que se expondrán, pululan en Colombia, debido a que numerosas construcciones se han levantado por personas de bajos recursos económicos, en terrenos no aptos para ello, y por la agreste geografía y variante clima de un país de trópico como Colombia; y a que -nadie se extrañe de un reconocimiento tan temprano pues de no ser así estas líneas no se necesitarían- la Corte Constitucional en sus primeros años se mostró en términos generales condescendiente con los entes administrativos encargados de dar solución a dichos eventos, para luego, en el Siglo XXI, mostrarse vigorosa e implacable frente a la administración pública. ¿Por qué intervino la Corte? y ¿Cuáles fueron las razones para estos momentos tan disímiles?, son preguntas que serán absueltas a lo largo del escrito.

La tesis, que se defenderá, consiste en que el desarrollo de normas programáticas, como lo son la vivienda digna y la prevención de desastres, reclaman la exigencia de intervención judicial, a causa de la inacción de los organismos competentes para efectuarlas, y que el acrecentamiento de la justiciabilidad, a través, de la acción de tutela ha tenido un avance progresivo que alcanza su madurez, de la mano de tendencias internacionales del garantismo constitucional.

Metodológicamente este ensayo es descriptivo-analítico, y se divide en cuatro partes: (i) en la primera se expondrán normativamente las competencias para la satisfacción de la vivienda digna y la prevención de desastres en zonas de alto riesgo, caracterizando las condiciones para 
que una vivienda se considere digna -lo que vale a "llenar" de contenido este derecho- para establecer, a partir de los principios de la función pública, las propiedades que debe tener la actuación administrativa frente a ellas; (ii) luego se auscultarán las decisiones de la Corte Constitucional, en la materia de este escrito, en el periodo de "actitud pasiva", que comprende la década de los años 90; (iii) para posteriormente, hacer una crítica a estas decisiones, con apoyo en la doctrina extranjera a esta postura: Atienza, pero sobre todo Pisarello, será la punta de lanza; (iv) enseguida se recalará en las sentencias de "la década activa", correspondiente al siglo XXI de la Corte. (v) Finalmente, se recogerán las conclusiones de este ensayo.

\section{VIVIENDA DIGNAY ZONAS DE ALTO RIESGO}

\subsection{El procedimiento administrativo para la mitigación y superación del peligro que afecta las viviendas ubicadas en zonas de alto riesgo}

El derecho social a la Vivienda Digna surge con los derechos Económicos, Sociales y Culturales, los cuales el legislador colombiano consagró de manera en la Constitución Política de Colombia en el capítulo denominado "De los derechos sociales, económicos y culturales" (Título I. Cap. 2). La carta política ya referida, estableció a su vez, el derecho a la vivienda digna, el cual dispone que:

Todos los colombianos tienen derecho a vivienda digna. El Estado fijará las condiciones necesarias para hacer efectivo este derecho y promoverá planes de vivienda de interés social, sistemas adecuados de financiación a largo plazo y formas asociativas de ejecución de estos programas de vivienda. (art. $51)$.

De lo anterior, se interpreta que el constituyente quiso que el ejecutivo fuera la rama pública sobre la cual recayera toda la estrategia para hacer efectivo este derecho, que necesariamente requería una correlación entre el sector bancario y el relacionado con la construcción, contemplándolos dentro del alcance legal, que el Congreso de la República decidiera darle. Por ello, el Estado es el que debe adelantar las acciones sociales y destinar los recursos necesarios, para el desarrollo de políticas concretas de vivienda en todo el país. Dichas políticas pueden ser realizadas de 
forma directa o por medio de un contratista privado, siempre y cuando la relación entre ambos esté conforme a la ley.

Legalmente, la primera norma que reguló la elaboración de los planes de desarrollo municipal, para el manejo del espacio público, de modo que se garantizasen las condiciones apropiadas para el desarrollo de las ciudades, fue la Ley $9^{a}$ de 1989. Antes de esta ley, la normatividad en Colombia sobre la planificación del desarrollo municipal era prácticamente inexistente, poco técnica y estaba dispersa, por lo que su expedición, comporta la respuesta - un poco tardía- del Estado para afrontar los avances de la sociedad colombiana, que ha dejado de ser rural y se hace más compleja en asuntos urbanísticos, puesto que supone una tecnificación en el uso tanto del espacio público, como de las normas urbanísticas, en procura de hacer más seguros, entre otros, los asentamientos urbanos que se pretenda realizar o que ya existan, de modo tal, que el desarrollo de las ciudades se lleve a cabo, mediante la formulación de un plan de desarrollo por parte de las entidades municipales.

La Ley 9a de 1989 (art. 10), declara de utilidad pública o interés social, la adquisición de bienes inmuebles urbanos o suburbanos para destinarlos, entre otros, a la reubicación de asentamientos humanos ubicados en sectores de alto riesgo; así mismo, la referida ley (art. 56, Modificado por el art. 5 de la Ley $2^{\text {a }}$ de 1991), preceptúa la primera medida para afrontar los problemas que estos sitios marginales padecen, al encomendar a los alcaldes municipales levantar y mantener actualizado un inventario de las zonas que presenten altos riesgos para la localización de asentamientos humanos por ser inundables, sujetas a derrumbes o deslizamientos, o que de otra forma presenten condiciones insalubres para la vivienda. Además, les ordena adelantar: o (i) programas de reubicación de los habitantes que allí se ubiquen, $\mathrm{u}$ (ii) operaciones que permitan eliminar el riesgo en los asentamientos localizados en dichas zonas; y les da otras indicaciones para evitar el repoblamiento de tales sectores. De modo que, se reconoce cierto margen de discrecionalidad a la administración municipal para que, a partir de estudios técnicos realice un razonamiento predictivo, y establezca cuál de estas dos opciones se plantea como la más eficaz para asegurar la no existencia de riesgos en su territorio ${ }^{1}$.

Con la Ley $9^{\text {a }}$ de 1989 (art. 10) se crea el Sistema de Vivienda de Interés Social, modelo de vivienda que el Estado se ha propuesto entregar a las

1 Se trata pues de una regla de fin. Sobre ellas ver Manuel ATIENZA, El derecho como argumentación, Barcelona, Ariel, 2006, p. 165 y s.s. 
personas de escasos recursos. Pero, este primer elemento definitorio de vivienda de interés social carecía de profundidad y era rudimentario pues se edificaba únicamente según el costo de la misma².

Meses después, mediante el Decreto-Ley 919 de 1989 -que estuvo vigente en el lapso en el que se profirieron las sentencias que más adelante se analizarán- se crea el Sistema Nacional para la Prevención y Atención de Desastres, dentro del cual se fija que las entidades territoriales -Departamentos y Municipios- deben "atender las recomendaciones que en materia de prevención, atención y rehabilitación les formulen los Comités Regionales y Locales" (art. 62, Lit. h), quienes tienen a cargo la realización de estudios e investigaciones "sobre la ocurrencia de desastres (...) amenazas, análisis de condiciones de vulnerabilidad y de evaluación de riesgos" (art. 61, Num. 2, Lit. c).

La irrupción de la Constitución Política de Colombia de 1991 (art. 31), vino a reafirmar la competencia del Municipio, como ente territorial encargado de solucionar los problemas, generados por el clima que afecten a las viviendas, al asignarle de manera general, la competencia para construir las obras que demande el progreso local y ordenar el desarrollo de su territorio, así como asignando a los departamentos una función de complementariedad a la acción municipal, fungiendo como intermediario entre la Nación y los municipios. La propuesta era clara: un Estado unitario con descentralización administrativa, en donde tal y como lo interpreta Hernández (2008) el municipio está "en la vanguardia de la lucha nacional contra la pobreza, en donde se le pide que se convierta en auténtica escuela de la democracia y le exige transformarse en un promotor del desarrollo económico" (p.96).

Posteriormente se expide la Ley 388 de 1997 que regula de manera íntegra la prevención de desastres dentro de la planeación del ordenamiento territorial municipal, actualizando así la Ley 9a de 1989. Uno de sus objetivos es el "establecimiento de mecanismos que permitan al municipio (...) la prevención de desastres en asentamientos de alto riesgo, así como la ejecución de acciones urbanísticas eficientes" (art. 1.2). La misma define como un elemento del componente general del plan de desarrollo de cada municipio "la determinación y ubicación en planos de las zonas que presenten alto riesgo para la localización de asentamientos humanos, por amenazas o riesgos naturales o por

2 Los topes eran los siguientes: menos 100 salarios mínimos en ciudades con 100 mil habitantes o menos; inferior o igual a 120 salarios mínimos en ciudades entre 100 mil y 500 mil habitantes, e inferior o igual a 135 salarios mínimos en ciudades con más de 500 mil habitantes. 
condiciones de insalubridad" (Art. 12.2.3). Del mismo modo, (arts. 13.5 y 15. 3.2.), incorpora dentro del componente urbano del plan de ordenamiento, la realización de planes a mediano plazo para reubicar los asentamientos urbanos localizados en zonas de alto riesgo o insalubres, debiendo identificar terrenos para tal fin.

Esta competencia en cabeza del municipio sería reiterada por la Ley 715 de 2001 (art. 76. 2), al conferir el deber de prevenir y atender los desastres que ocurran en su jurisdicción, adecuar las áreas urbanas y rurales en zonas de alto riesgo y reubicación de asentamientos, y promover programas o proyectos de vivienda de interés social según la disponibilidad de recursos.

Recientemente el Congreso de la República expidió la Ley 1523 de 2012 (art. 40) mediante la cual se establece el Sistema Nacional de Gestión del Riesgo de Desastres - la actualización normativa del manejo del riesgo en Colombia-, en la cual se ordena a los municipios, distritos y áreas metropolitanas incorporar, en sus planes de desarrollo y de ordenamiento territorial, los programas y proyectos prioritarios para garantizar el desarrollo seguro y sostenible, de la gestión del riesgo, articulando para ello, las herramientas previstas en la Leyes $9^{a}$ de 1989 y 388 de 1997, para el señalamiento, delimitación y tratamiento de las zonas expuestas a amenazas derivadas de fenómenos naturales, socio-naturales o antropogénicos no intencionales, junto con los mecanismos para la reubicación de los asentamientos situados en zonas de alto riesgo, para evitar los reasentamientos, a través, de la adquisición y expropiación de inmuebles que sean necesarios, con el fin de lograr la reubicación de poblaciones en alto riesgo.

El modo principal en que el Estado ha enfocado sus esfuerzos para proveer soluciones a la necesidad de vivienda digna, es a través de planes de vivienda de interés social, en los que, los municipios deben actuar en concurrencia, coordinación y complementariedad, con los departamentos y la Nación, de acuerdo al Plan Nacional de Desarrollo adoptado por el Gobierno Nacional y el presupuesto de cada año. Según la catedrática Robledo (2010), en este marco, al municipio le corresponde (a) identificar las necesidades locales de vivienda; (b) localizar terrenos aptos en donde desarrollar los planes de vivienda; (c) entregar subsidios de vivienda.

De la anterior descripción normativa, se puede obtener cuatro conclusiones: (i) la afectación de la viviendas por estar ubicadas en zonas 
de alto riesgo es de aquellos desastres que la administración debe evitar; (ii) consecuencialmente se ordena la reubicación de sus habitantes; (iii) la cual implica el desarrollo de planes de vivienda de interés social; (iv) en cuyo inicio y desarrollo no están llamados los jueces; (v) no se establecen términos fijos para realizar la prevención del riesgo e inicio de los programas de viviendas ${ }^{3}$.

\subsection{Características que validan la actuación administrativa}

La carencia de términos temporales para el desarrollo de todas las competencias plantea la necesidad de establecer criterios que logren desarrollar y limitar esa discrecionalidad con que cuenta la administración para iniciar programas de vivienda.

La respuesta a esta inquietud debe sin duda alguna, partir de la Constitución Política de Colombia (art. 209), el cual establece que la función administrativa debe desarrollarse con fundamento, entre otros, de los principios de eficacia, economía y celeridad.

Ha dicho nuestro Tribunal Constitucional (Sentencia T-220, 1994), que cuando la Constitución se refiere a la eficacia administrativa propende porque los funcionarios públicos resuelvan de manera oportuna las peticiones y necesidades provenientes de los coasociados, lo cual se manifiesta en tres exigencias: (i) una manifestación adecuada a la solicitud; (ii) una respuesta efectiva para el caso planteado, y (iii) una comunicación oportuna (que no sea tardía), lo cual resalta por su importancia cuando se le exige a la administración ser celera, que en concepto de la Corte Constitucional supone tener:

(...) agilidad en el cumplimiento de las tareas a cargo (...) para lograr que alcancen sus cometidos básicos con prontitud, asegurando que el efecto de su gestión se proyecte oportunamente en la atención de las necesidades $\mathrm{y}$ aspiraciones de sus destinatarios. (Sentencia T-731, 1998).

Así mismo, la Corte Constitucional ha enfatizado que el principio de economía "constituye una orientación, una pauta, para que el cumplimiento de los fines del Estado se proyecte buscando el mayor beneficio social al menor costo" (sentencia C-849, 2005). 
Para Santofimio (2007), los principios de economía, celeridad y eficacia en cuanto a la administración pública son así elementos del derecho fundamental al debido proceso que exige procedimientos sin dilaciones injustificadas, buscando que las actuaciones se cumplan en el menor tiempo posible, de modo tal que se permita proteger al ciudadano otorgándole las garantías indispensables y logrando decisiones de fondo para que las autoridades hagan realidad los fines para los cuales han sido instituidas.

El desarrollo de programas estatales para satisfacer el derecho a la vivienda digna debe tener como guía estos parámetros.

\subsection{El contenido del derecho a la vivienda digna}

La importancia del derecho a la vivienda digna parte de la lógica de que se debe contar con una vivienda para poder albergar a la familia, aquella, que nuestra Constitución Política, ha dispuesto como "institución básica de la sociedad"(art. 5).

En efecto, el derecho a la vivienda digna permite el desenvolvimiento de una vida decorosa de una persona en su entorno familiar, social y ambiental. Es precisamente, en cada vivienda en donde se desarrolla la familia, y cada individuo que la compone, tiene un espacio para desenvolverse, permitiendo a padres e hijos crecer juntos. En una vivienda se celebran cumpleaños, reuniones sociales, se comparte, pero lo que lo hace diferente de cualquier otro lugar en todo el planeta, es el momento de intimidad que se tiene. Estar en casa, permite tener la libertad de actuar y hacer lo que se quiera, siempre y cuando no sea contrario a las leyes naturales y positivas, que en últimas, permite materializar por unos momentos, la idea de ser feliz, o en su otro caso extremo, da el espacio necesario para estar triste y desahogarse.

El propósito es satisfacer la condición humana de tener un lugar en donde se desarrollen satisfactoriamente las necesidades propias del ser humano como el proporcionar albergue contra el clima, alimentación adecuada, descanso, seguridad de ser la barrera contra agentes físicos y biológicos, y constituir el ambiente adecuado para el perfeccionamiento de los derechos fundamentales de todo tipo, en especial la intimidad y el libre desarrollo de la personalidad, siempre y cuando cumpla con unas condiciones especiales que permitan el correcto desarrollo de sus ocupantes así como preservar su dignidad. 
Por ello, hay que argumentar el hecho bajo el cual, para poder compartir momentos de gozo, reponerse de un fracaso, y permitir el desarrollo de la personalidad de cada integrante de la familia, ese espacio debe ser digno, por ello la importancia de este derecho constitucional, tanto así, que la Corte Constitucional lo ha definido como aquel "dirigido a satisfacer la necesidad humana de disponer de un sitio de residencia, sea propio o ajeno, que ofrezca condiciones mínimas para que quienes allí habiten puedan realizar su proyecto de vida" (Sentencia C-300, 2011).

El derecho a Vivienda Digna, comprende por lo tanto, la posibilidad de adquirir o bien gozar de la tenencia de una propiedad, principalmente por personas de escasos recursos, a través de la promoción de políticas tendentes a la creación y acceso de viviendas.

Pero jurídicamente, ¿qué criterios delimitan lo 'digno' de una vivienda? La Constitución Política colombiana de 1991 como es de esperar, no dice mucho. Así entonces, es útil acudir a la Observación General $\mathrm{N}^{\circ} 4$ proferida por el Comité de Derechos Económicos, Sociales y Culturales por medio de la cual expone una serie de factores para que una vivienda se considere como adecuada ${ }^{4}$, cuales son: (i) Que tenga una disponibilidad de servicios, materiales, facilidades e infraestructura con los que se garantice la salud, la seguridad, la comodidad y la nutrición; (ii) que los gastos que ella demanda sean soportables, para que su apropiación y mantenimiento no imposibiliten la satisfacción de otras necesidades; (iii) que sea habitable, en el sentido de que proteja a quienes la utilizan de los elementos de la naturaleza; (iv) que sea asequible a todos, dándole prioridad a los "grupos desfavorecidos"; (v) que se encuentre en un lugar que permita el normal desarrollo de la vida social de sus habitantes; (vi) que sea construida de modo que no restrinja la identidad cultural.

Sobre la aplicación judicial de la jurisprudencia y doctrina de los organismos internacionales de derechos humanos encargados de la interpretación de los tratados sobre derechos humanos, como el CDESC, ha dicho nuestro Tribunal Constitucional que constituye "un criterio hermenéutico relevante para establecer el sentido de las normas constitucionales sobre derechos fundamentales" (Sentencia C-010, 2000).

4 La Corte Constitucional de Colombia en Sentencia T-235, 2011 (M.P. Luís Ernesto Vargas: Marzo 31 de 2011) precisa que los conceptos "vivienda digna" de la Constitución colombiana de 1991, y "vivienda adecuada" del derecho internacional no son idénticos, pues uno y otro pueden establecer estándares superiores de protección, pero que en todo caso, en aplicación del principio pro homine el Juez constitucional en cada caso debe escoger el que ofrezca una protección mayor. 
Así, respecto a la Observación General $\mathrm{N}^{\circ} 4$, la Corte Constitucional ha destacado su importancia ya que es un referente interpretativo que "establece criterios para determinar el contenido del artículo 51 constitucional" (Sentencia T-495, 2010).

Debe advertirse que la Corte Constitucional de Colombia en Sentencia T235 de 2011 (M.P. Luís Ernesto Vargas: Marzo 31 de 2011) precisa que los conceptos "vivienda digna" de la Constitución colombiana de 1991, y "vivienda adecuada" del derecho internacional no son idénticos, pues uno y otro pueden establecer estándares superiores de protección, pero que en todo caso, en aplicación del principio pro hómine el Juez constitucional en cada caso debe escoger el que ofrezca una protección mayor.

Sin embargo, las características físicas y especiales con las que se construye una vivienda digna, no agotan el contenido de este derecho social. El CDESC (observación General $\mathrm{N}^{\circ} 4$, art. 8) señala que los Estados deben garantizar a dueños y poseedores de las viviendas una seguridad jurídica en la tenencia, con lo que ha de protegerse del desahucio, el hostigamiento u otras amenazas.

Esta referencia pone de presente que desde el momento en que una persona logra obtener una vivienda digna, bien sea a través de un programa gubernamental o por sus propios recursos, las prerrogativas que se desprenden del artículo 51 superior se transforman, por lo que el derecho a la vivienda digna, tal como lo preceptúa la Corte Constitucional "adquiere la configuración de un derecho de defensa frente a injerencias arbitrarias de las autoridades estatales o de particulares" (Sentencia T-1318, 2005), sin importar, por ejemplo, que su dueño sea o no un sujeto de especial protección constitucional. En este plano es donde se manifiesta, preponderante pero no exclusivamente, la garantía de preservar la vivienda como elemento principal del plan de vida que cada quien se ha determinado.

\section{LA CORTE PASIVA}

Las sentencias que se analizan en este ensayo tienen como sustrato fáctico común, que los accionantes eran familias de escasos recursos que a causa de fenómenos naturales veían afectada la estabilidad de sus viviendas. Las tres primeras que aquí se analizarán, corresponden a aquellas en las que la Corte apenas profirió exhortos o dio recomendaciones a la administración, sin acceder a las pretensiones 
elevadas en las demandas de tutelas. Particularmente, estas sentencias son temporalmente las primeras del grupo recopilado en el punto de derecho de este ensayo.

(i) En la primera sentencia T-021 de 1995, la accionante plantea que a causa de un movimiento sísmico se produjo un alud de tierra, que tapó parcialmente el inquilinato donde vivía. El inmueble con el que colinda la vivienda de la accionante, es propiedad del Distrito de Bogotá, el cual también resultó afectado y amenaza con derrumbarse. Ante esta situación, la demandante solicita la remoción de la tierra que ha turbado su residencia y la construcción de un muro de contención que evite la plena destrucción del inquilinato. Esta situación fue catalogada por la Oficina para la Prevención de Emergencias como grave, y precisa que también será de alto riesgo en cuanto se empiece a realizar cualquier proceso para estabilizar el alud en la parte posterior de la vivienda.

Dicho concepto técnico, lleva a la Corte (sentencia T-021 de 1995) a considerar que una eventual intervención al alud solo generaría más riesgo sobre la vida de los afectados. Para la misma, es "de sentido común que no todos los problemas tienen respuestas en la acción de tutela" (sentencia T-021 de 1995), por ello, el tribunal (sentencia T-021 de 1995) exhorta en su parte motiva al Distrito para que adquiera el inmueble como solución inmediata y que tome las medidas preventivas para que no sea posteriormente habitado por otras personas, trayendo a colación el cumplimiento del artículo $10^{\circ}$ de la Ley $9^{a}$ de 1989 . A partir del dinero obtenido por la venta o expropiación, explica la Corte, la accionante puede comprar otro inmueble que supla al que tenía. Finalmente el cancerbero constitucional señala que las recomendaciones expuestas deberán ser apreciadas por el Distrito Capital en su justa dimensión, a pesar que habían transcurrido cerca de 10 meses entre los hechos que motivaron la demanda de acción tutela y esta sentencia.

(ii) En la segunda sentencia, identificada como T-258 de 1997, los accionantes buscan protección ante la vulneración de su derecho a Vivienda Digna, basados en la precaria reubicación realizada por la administración del municipio de Yumbo, quién mediante INVIYUMBO, la cual trasladó a varias familias que habitaban en una zona de alto riesgo, específicamente de las laderas del río Yumbo, a una zona industrial, en la cual los habitantes encontraron falencias que les desmejoraron su calidad de vida, por cuanto las personas: reciben la 
contaminación proveniente de las empresas industriales, el asentamiento no reúne el espacio permitido para la habitabilidad del inmueble de las familias reubicadas, el terreno es inestable por cuanto antes había un basurero y la tierra no tuvo el tratamiento adecuado para la construcción, no tienen servicios de transporte, ni existen centros de salud o educativos cerca. Además de lo anterior, señalan que en época de invierno el sector se inunda.

La defensa judicial del ente territorial se fundó bajo el entendido de que había realizado una inversión que eliminó la situación de alto riesgo, no obstante lo anterior, se suscribió un acta de compromiso con la comunidad, para solucionar las controversias que muestra la urbanización a donde dichas personas fueron trasladadas.

La primera instancia consideró que la reubicación no había mejorado las necesidades mínimas de los grupos familiares, puesto que el restringido espacio de las nuevas viviendas ( 25 metro cuadrados) y su deficiente construcción llevaría a las familias a vivir en un hacinamiento total o a separarse para vivir en varias viviendas.

Sin embargo el ad quem revocó el fallo, decisión que fue confirmada por la Corte Constitucional bajo el entendido que el desarrollo por parte de las autoridades municipales de planes de vivienda para ubicar en ellas a quienes viven en zonas de alto riesgo no violenta derecho alguno. Tal medida, en criterio de la Corte, demuestra de parte del ente territorial demandado "su interés en buscar la solución a los problemas que por aguas lluvias y obras de infraestructura se han presentado a dichas viviendas" (Sentencia T-258, 1997). El tribunal ya referido (Sentencia $\mathrm{T}-258,1997)$ sobre la contaminación ambiental, señaló que era una situación que afectaba a toda la municipalidad, y que no se exponía a una mayor a los accionantes, que los demás habitantes. Sobre el derecho a la vivienda digna recordó su naturaleza programática, esto es la dependencia a las condiciones de capacidad económica del Estado para obtener su efectiva materialización. Para la Corte Constitucional este derecho:

junto con otros derechos de carácter económico, no tiene la protección inmediata que le puede brindar la acción de tutela, pues en su condición de derecho asistencial, le corresponde al Estado la obligación de desarrollar planes de vivienda, ya sea directamente o por medio de contratos con particulares, todo de acuerdo con la ley. Por tal motivo, las condiciones jurídicas, 
económicas y materiales son las que determinarán la efectiva materialización de tal derecho. (Sentencia T-258, 1997)

(iii) En la Sentencia T-1689 de 2000, la accionante sufrió a causa de una obra transversal realizada por una administración municipal, el deterioro en la estructura física de la vivienda del accionante, hasta quedar a punto de derrumbarse por el deslizamiento del terreno, poniendo en peligro inminente el derecho a la vivienda digna y la vida de sus moradores. Antes de incoarse la acción de tutela el damnificado puso en conocimiento su situación a diferentes autoridades municipales, a través de tres derechos de petición, obteniendo respuesta únicamente de la Personería Municipal. Las entidades del Gobierno Municipal solo se pronunciaron dentro del trámite de la acción de tutela argumentando que no había negligencia de su parte, como lo constata el inicio de obra de una tubería que aislará del deslizamiento en tres de los 33 metros que se necesitan para la solución del problema. Agregan que le ofrecieron a la actora construir dos habitaciones en una zona estable del mismo predio, si decidía desocupar 2 en las que se amenaza el peligro inminente, y que se ejecutarán otras de manera que se pueda garantizar el funcionamiento de la obra.

Al decidir la Corte el caso, confirma la sentencia de segunda instancia, la cual revoca la de primera, que había conferido el amparo solicitado, y se limita a prevenir al Alcalde Municipal, a fin de que gestione lo más rápido posible, la ejecución de las obras necesarias para evitar que el deslizamiento continúe. Como fundamento de su decisión la Corte consideró que la tutela no es el medio idóneo para ordenar:

(...) que se lleve a cabo determinada obra pública por el solo hecho de estar prevista en el Presupuesto una partida que la autoriza. Llevaría a un co-gobierno de la rama judicial en abierta violación del artículo 113 de la Carta Política, desnaturalizaría el concepto de gestión administrativa y haría irresponsable al Gobierno por la ejecución del Presupuesto, en cuanto ella pasaría a depender de las determinaciones judiciales. (Sentencia T-1689, 2000).

Respecto del derecho a la vivienda digna no emitió pronunciamiento alguno. Se observa pues una confianza excesiva en la capacidad de la administración pública, a quien no se le fija un término para solucionar una situación que afectaba los intereses de los accionantes. 


\section{RAZONES PARA LA JUSTICIABILIDAD DEL DERECHO A LA VIVIENDA DIGNA}

Sea lo primero resaltar el carácter de directriz programática del derecho a la vivienda digna, en su faceta de prestación para garantizar el acceso y mantener las condiciones materiales de las viviendas, y la prevención de desastres. Sobre este tipo de normas, Ruíz Manero (2005), profesor de la Universidad de Alicante, ha dicho que: "establecen la obligatoriedad de perseguir determinados objetivos colectivos, esto es, de maximizar ciertos rasgos o propiedades del mundo social" (p. 345). Como complemento de lo anterior, Atienza \& Ruíz Manero (1996) establecen que están a cargo de los organismos con legitimación democrática -legislador y ejecutivo-, quienes cuentan con un cierto margen de discrecionalidad para su desarrollo debido a que su implementación debe atender a condiciones de oportunidad, capacidad y necesidad.

El catedrático Ruíz Manero (2005) plantea que los objetivos perseguidos por las directrices se caracterizan ya que 1) ordenan un estado de cosas que pueden mantener relaciones causales con acciones heterogéneas entre sí, es decir, que el objetivo mandado se puede cumplir con diversos medios; lo cual lleva a que 2) se pueda tener relaciones causales con estados de cosas ordenados por otras directrices, esto significa que son interdependientes: unos medios idóneos para obtener determinados fines pueden resultar ayudando o afectando la consecución de otros objetivos; 3) ese estado de cosas ordenado es graduable, de allí que puedan realizarse en la mayor medida de lo posible, y 4) el deber de maximización es un deber concluyente.

El profesor español Atienza (2010) sostiene que para sortear las dificultades que pudieran presentar la esencia de las normas programáticas, se hace necesaria la articulación de políticas. En efecto, a través de una "ponderación de concreción", el legislador o ejecutivo deben establecer medidas conducentes a desarrollar cada una de las múltiples directrices, ya mediante la formulación de una regla de acción, de fin (ej: art. 56 Ley 9/89) o una medida concreta (reubicar un barrio).

Por lo anterior, dicen los profesores españoles, la intervención judicial en el desarrollo de normas programáticas resulta excepcional ya que solo puede darse cuando (i) se adopten medios inidóneos para satisfacer la 
directriz o que el adoptado afecte a otras o (ii) simplemente no se haga nada, o sea no se desarrollen políticas para su cumplimiento (Atienza \& Ruíz Manero, 1996).

Esta última referencia, es la materialización en el campo de la argumentación jurídica del amplio espectro del garantismo constitucional al que se hacía referencia en los preliminares de este escrito. Sencillez y efectividad son adjetivos que se pueden predicar de la síntesis formulada por Atienza y Ruíz Manero de un tema que ha suscitado importantes debates en el plano internacional y desde luego nacional en defensa de la justiciabilidad de los derechos sociales.

De la lectura del texto constitucional y las sentencias atrás reseñadas podría concluirse que los derechos sociales en Colombia sufren una "orfandad" en materia de acciones constitucionales. En efecto el constituyente primario no previó expresamente una acción constitucional específica con qué defenderlo, como sí lo hizo con los derechos fundamentales y los derechos colectivos, al establecer la acción de tutela y la acción popular, respectivamente.

Si se ha adoptado la Constitución como norma de normas dentro del ordenamiento jurídico colombiano, ordenándose especialmente a los servidores públicos su garantía (artículo 4 superior), mal puede propiciarse la ineficacia de derechos constitucionales como la vivienda digna y demás derechos sociales. Sobre esta situación problemática, Pisarello (2007) ha dicho que:

(...) no son las garantías concretas que se asignan a un derecho lo que determina su carácter fundamental sino a la inversa: es su consagración positiva en aquellas normas consideradas fundamentales lo que obliga a los operadores jurídicos a maximizar, bien por vía de interpretación, bien por medio de reformas, los mecanismos que permitan su protección (...) la ausencia de garantías legislativas o jurisdiccionales de un derecho constitucional no tendría por qué equipararse a ausencia de fundamentalidad (...) un derecho sin garantías debería verse como un derecho inactuado. (p. 81).

Esta exigencia de interpretación a los jueces para hacer justiciables los derechos sociales, no significa más que ahondar en el esfuerzo, que desde hace cuatro siglos compromete al hombre occidental, de la protección de sus derechos e intereses. 
Se advierte al lector, que la Corte Constitucional ha hecho justiciable al derecho a la vivienda digna, considerándolo en la actualidad "que constituye un derecho fundamental autónomo, debido a su estrecha relación con la dignidad humana" (Sentencia C-359, 2013) ${ }^{5}$. Veamos, como fue en tratándose de los habitantes de zonas de alto riesgo.

\section{LA DÉCADA ACTIVA}

(i) En la Sentencia T-1094 del 2002 la Corte Constitucional estableció reglas frente a situaciones de desastres naturales y zonas de alto riesgo. Ubicó la problemática que tiene la actora, propietaria de un predio en donde habitaba pero que se vio amenazado con desplomarse por causa de un gran depósito aluvial, por lo que tuvo que desalojarlo, abandonando sus cultivos. El primer deslizamiento ocurrió 15 meses antes de interponerse la tutela, y en ella pidió ser reubicada e indemnizada por el lucro cesante que le produjo no tener ingresos por el ejercicio de su actividad agrícola.

Dentro del proceso de tutela se demostró que la accionante no obtuvo la respectiva licencia para construir en el terreno donde se ubicaba su casa, y que el Municipio había contratado con una empresa aseguradora un seguro catastral solo para los predios ubicados dentro del mismo que al momento del desastre (incendio, explosión, daños por agua, etc.) estuviesen a paz y salvo con el impuesto predial; a partir del cual los beneficiarios recibirían una indemnización correspondiente a un dinero proporcional al avalúo catastral de la construcción que estuviera registrado en la oficina de catastro departamental o municipal al momento del siniestro. A partir de este seguro se demostró que a la accionante se le había entregado un cheque por concepto de indemnización por los daños ocasionados a su vivienda. La oficina de medio ambiente y de planeación catalogó la zona de la accionante como de alto riesgo.

Al momento en que la Corte Constitucional conoce el asunto, concluye que la prestación dada es insuficiente y ordena al Municipio que decida en plazo razonable de tres meses si realiza o no la expropiación del inmueble de la actora; y que en caso contario incluyan a la accionante así como a su familia en los planes de urbanismo y vivienda social; y en el entretanto debe proveer de un alojamiento digno a la familia de la tutelante por 180 días máximo.

5 Una valiosa síntesis de la evolución de las tesis de tutela de los derechos sociales por parte de la Corte puede verse en: Julián Daniel LÓPEZ, Alfredo José BATEMAN, Juliana VENGOECHEA y Juanita María LÓPEZ, La garantía de los derechos sociales, Bogotá, Universidad Pontificia Javeriana, 2009, pp. 113-125. 
(ii) Posteriormente, la Corte Constitucional en la Sentencia T-894 del 2005 revisó la sentencia de tutela en la que aduce la actora que está imposibilitada para habitar su vivienda debido a las características del terreno en donde está construida, por cuanto se vio afectada por efecto de la erosión, y agrietamiento que amenaza seriamente con desplomarse, acabando así la dulce vida de ella y su familia, en donde habitan 5 menores de edad. Previamente la entidad municipal competente había calificado la propiedad como de zona de alto riesgo. Con todo, la parte actora solicita la reubicación de su familia sin llenar los requisitos de los planes de vivienda que otorgaba el municipio, como lo eran el ahorro previo y el concurso. En el proceso se aportó la prueba de que el compañero permanente de la tutelante, había abierto una cuenta de ahorro programado con saldo de $\$ 303.767 .85$, en señal de empezar el cumplimiento de los requisitos pero que dado que percibían como ingresos, bajos recursos y lo que gana solo les alcanza para su subsistencia, su capacidad de ahorro es mínima. Previamente en respuesta a sus derechos de petición, el ente territorial le indicó que debía concursar en la bolsa ordinaria a través de COMFAMILIAR para acceder a los programas de vivienda, argumento que fue reiterado en sede judicial.

El a quo negó la acción de tutela por cuanto la misma no puede obviar el cumplimiento de los requisitos legales para acceder a vivienda de interés social, decisión confirmada en segunda instancia.

En cambio, la Corte Constitucional revocó los fallos de instancia y en su lugar concedió la tutela, por cuanto determinó que no había duda del riesgo de peligro inminente que amenazaba la vida de la familia, en la que vivían cinco menores de edad, uno de ellos afectado por Síndrome de Down, que conforme a los tratados internacionales así como a la misma Constitución gozan de un protección reforzada y especial para garantizar una vivienda en donde puedan desarrollarse en mínimas condiciones de dignidad. Por ello, ordenó la reubicación de la vivienda de la familia en un término de 60 días, advirtiendo que el requisito de la apertura de ahorro programado para acceder al subsidio familiar de vivienda había sido satisfecho.

(iii) La sexta sentencia que revisó la Corte Constitucional (sentencia T199, 2010), contiene en su parte fáctica la construcción de viviendas de interés social, por parte del ente territorial del municipio de Caracolí, en una zona que da pie para que los inmuebles de todo el barrio construido, 
se vean afectados por continuos desprendimientos de rocas y deslizamientos de tierras.

Los accionantes refieren que desde el año 1998 han dirigido diversas peticiones a la administración municipal, con la finalidad de que se adopten medidas para estabilizar los terrenos donde están construidos sus hogares, pero que hasta la fecha de la presentación de tutela, tales solicitudes han sido infructuosas, por cuanto no se ha tomado ninguna medida importante al respecto.

La tutela trae a colación las diversas actuaciones que ha llevado a cabo la administración municipal para atender sus requerimientos: (i) en el año 2000 los visitó la Comisión de prevención de desastres, cuya única recomendación fue que sembraran plantas (brachiaria) para contener el deslizamiento de tierra; (ii) en el año 2006 se realizó una nueva visita, a cargo de una ingeniera del municipio quien les recomendó que mantuvieran los árboles podados; (iii) en octubre de 2008 y (iv) el 15 de abril de 2009 nuevamente tuvieron lugar inspecciones oculares de funcionarios municipales, quienes se limitaron a tomar fotografías y a realizar mediciones del terreno afectado.

Como argumento de defensa, el alcalde del municipio referido argumenta no ser responsable de los hechos, ya que el ente territorial no intervino en la construcción de las viviendas afectadas, puesto que su construcción corrió a cargo de un organismo de carácter nacional y como se trata de inmuebles de propiedad privada (no pertenecen al municipio), no se debe invertir en ellos los recursos públicos, y que tampoco le compete adoptar las medidas necesarias para frenar las calamidades, porque la zona no ha sido previamente calificada como de alto riesgo.

La Corte Constitucional concede la protección solicitada, en especial el derecho a vivienda digna, por más de que no fue aducido por los accionantes. El alto tribunal, justifica su decisión haciendo referencia a la Observancia General 4 del Comité de Derechos Económicos, Sociales y Culturales, en donde se establecieron 7 condiciones para configurar el derecho a Vivienda Adecuada, distinguiendo entre ellas la habitabilidad, referidas en este artículo. Específicamente, el tribunal referido resaltó de este instrumento internacional, "la prevención de riesgos estructurales y la garantía de la seguridad física de los ocupantes" (CDESC, observación General $N^{\circ} 4$, art. 8), elementos de dicho concepto. 
La Corte Constitucional también resalta la amenaza que se cierne sobre la seguridad personal de todos los habitantes:

Debido a la inestabilidad del terreno en donde se levantan viviendas habitadas, porque en este tipo de eventos, y de acuerdo con las características del caso concreto los residentes pueden estar expuestos a riesgos extraordinarios que no están obligados a soportar y frente a los cuales las autoridades públicas deben adoptar medidas específicas de protección. (Sentencia T-199, 2010).

(iii) Posteriormente, en la sentencia T-199 de 2010 la Corte hace referencia a que las autoridades municipales sí tienen competencias en la prevención y atención de desastres en todas las zonas de la ciudad y no únicamente en las de alto riesgo, con un respaldo jurídico en la Ley 388 de 1997, el artículo 62 del Decreto Ley 919 de 1989 y el art. 76 de la Ley 715 de 2001, argumentando que aquellas competencias "no se reducen a las zonas de alto riesgo ni se agotan con la reubicación de asentamientos" (Sentencia T-199, 2010). Para terminar, el fallador constitucional establece que el juez de tutela sí puede incidir en el presupuesto de la administración y ordenar la construcción de una obra pública porque:

(...) se dispone que la autoridad destinataria debe adoptar un remedio específico (por ejemplo ordenar estudios técnicos, reubicar a los habitantes, reparar viviendas, incluir en programas de vivienda de interés social entre otros) que implica la ejecución de gastos. Igualmente es de anotar que las órdenes impartidas tienen una marcada tendencia a comprometer de manera más o menos intensa el comportamiento de la autoridad implicada, lo cual se explica por la gravedad de la situación y la inminencia del perjuicio al que estaban expuestos los accionantes. (Sentencia T-199, 2010).

Por las anteriores razones, en este caso la Corte resuelve: (a) que se adelantase una nueva visita para establecer el estado actual de las viviendas de los accionantes y las medidas a adoptar para precaver nuevos daños; (b) iniciar el procedimiento para declarar la zona en donde están ubicadas las viviendas como de alto riesgo, y (c) realizar la reubicación de sus habitantes. 


\section{CONCLUSIONES}

Con lo visto se tiene que las discusiones alrededor del derecho social a la vivienda digna dentro de la misma Corte Constitucional a lo largo del tiempo han llevado a reconocer su carácter como derecho fundamental. De allí abordó el estudio sobre las órdenes necesarias para materializar dicho derecho a falta del cumplimiento por parte de las autoridades administrativas por la omisión de los mandatos impuestos, que tienen una dimensión constitucional a partir de 1991 cuando empieza a regir la actual Carta Política. Esto demuestra que la actividad judicial tiene lugar ante una actividad insuficiente de la rama ejecutiva, para lo cual ha identificado ámbitos concretos de aplicación, como lo es la protección del derecho en cabeza de los habitantes de zonas de alto riesgo, en donde se ha corregido la aplicación de las políticas estatales.

Hacer justiciable, como se ha visto en la jurisprudencia de la Corte Constitucional, el derecho a la vivienda digna en este escenario es importante, pues la inacción e inoperancia estatal no puede ser admisible ya que la existencia de habitantes en zonas de alto riesgo de deslizamientos o avalanchas es de actualidad y una situación problemática para el país, que no puede ser solucionado de otra forma que proveyendo viviendas dignas para poder superar esa situación.

Se entiende que en Colombia el constituyente de 1991 al consagrar el artículo 51 reconoció un problema social, como lo es la falta de viviendas dignas para los colombianos. Pero esta consagración fue realizada con una suprema indeterminación y falta de concreción, puesto que no señala la forma concreta mediante la cual la administración pública debe garantizarlo al ciudadano, y tampoco consagra un medio de defensa del mismo

A continuación se expondrá desde un punto de vista crítico y analítico, las discusiones alrededor del derecho social a la vivienda digna, que provienen de su carácter como derecho fundamental; así como, se discutirán las acciones que se tomaron para materializar dicho derecho en gestiones concretas, todo esto, porque las medidas garantistas que originalmente se encomendaron a cargo de la administración pública, en el largo del tiempo que ha pasado, desde que entró a regir la Constitución Política de Colombia de 1991, han sido insuficientes, hasta haber llegado al punto en que la regulación más importante de este derecho ha sido 
producida por la rama judicial, para crear un ámbito concreto de aplicación de las políticas estatales, que de forma inmediata, protegen este derecho, desnaturalizando la labor que en su estado natural recayó en el Ejecutivo.

Se ha determinado el derecho a la Vivienda digna, enfocándose específicamente en las problemáticas que tienen las personas que cuentan con una vivienda ubicada en zonas de alto riesgo. Es supremamente relevante por cuanto esta problemática es actual y se ajusta a la realidad del país, en donde las noticias informan constantemente de historias tristes de colombianos que han perdido sus viviendas debido a desastres naturales, imprevistos, o como resultado de la inoperancia o de la falta de diligencia de la actuación estatal.

Para concluir, se entiende que en Colombia el constituyente creó una norma social, como lo es el derecho a la Vivienda digna, afectada por una suprema indeterminación y falta de concreción, puesto que no consagra un medio de defensa del mismo, ni la forma concreta mediante la cual la administración pública debe garantizar al ciudadano con base en los principios de eficacia, celeridad y economía, las condiciones para hacer efectivo este derecho.

Ahora, si bien es cierto que existe un desarrollo normativo en donde se establecen condiciones de aplicación de las normas por parte de la administración pública, esta ha sido pasiva, casi desinteresada. Al estudiar el comportamiento que tuvo la administración estatal en los diferentes casos referidos nunca se tomaron acciones inmediatas para proteger los derechos fundamentales, sino que siempre se escudó en diferentes razones para denegar la ayuda, haciendo caso omiso, precisamente, del principio de solidaridad y de los fines del Estado, consagrados en el artículo segundo de la Constitución Política de Colombia.

Con base en lo anterior, se destaca la labor de la Corte Constitucional puesto que es evidente que cumple con la carga para la cual fue creada, revisando eventualmente los casos más resonantes de orden nacional o bien sea pronunciándose en fallos de sentencias escogidas según sus propios criterios.

Entrando en materia, se reconocen en ella dos etapas: La primera corresponde a las sentencias: T-021 de 1995, T-258 de 1997 y T-1689 de 
2000. Estas, que se han denominado, como pertenecientes a una etapa pasiva, que se da en los primeros años de creación de la misma. Es completamente comprensible que un órgano jurisdiccional recién creado, que debía ajustarse a la realidad del país, cumpliera con emitir conceptos, esperando a que la administración los acate. Si bien la problemática fáctica en las sentencias es la misma, los fallos de la Corte no podían basarse en simples exhortos o decisiones en donde se reconociera la violación del derecho a la vivienda digna, sin expresar órdenes o acciones a ejecutar tendentes a garantizar el mismo. Es de rescatar, que este tribunal conoció del tema, pero antes de entrar a emitir órdenes o afectar el presupuesto municipal, dejó todo en manos de la administración estatal.

Hablar de la problemática estatal no es suficiente, en cambio, es de resaltar el cambio que tuvo la Corte Constitucional, por cuanto se consolidó en definitiva, como el órgano llamado a impedir los abusos, que en los casos planteados fueron notorios.

No se encuentra una razón para que en los casos de tutelas analizadas, la administración pública base su argumento aduciendo: (i) que el riesgo inminente ha desparecido, por medio de soluciones temporales, que en últimas son acciones insuficientes, como se observa en la Sentencia T1094 del 2002. Y si bien, en el caso de la Sentencia T-258 de 1997 se estableció un acta de compromiso para mejorar las condiciones en las que les fue son entregadas las viviendas, no protege el derecho en cuestión de forma inmediata.

Otro aspecto a analizar es el de los derechos de petición, dirigidos respetuosamente por los afectados, a la administración pública para que esta los escuchara ágilmente, y no tuvieran que acudir a la rama judicial como último recurso para encontrar solución y amparo a sus problemas, los cuales, no obtuvieron respuesta oportuna por parte de las entidades territoriales.

La siguiente etapa la constituyen las sentencias T-1094 del 2002, T894 del 2005 y T-199 de 2010. El cambio es notorio en la impartición de órdenes, en la protección inmediata a los derechos fundamentales invocados en peligro. En la primera sentencia, la Corte Constitucional le ordena al Municipio decidir sobre la expropiación del bien y que en caso contrario incluya a los accionantes en los planes de urbanismo y vivienda social, proveyéndoles en el intermedio de esto de alojamiento digno por un plazo máximo de 180 días; el avance 
continúa, cuando el tribunal constitucional en la Sentencia de T-894 de 2005 empieza a sentar el concepto de protección del riesgo inminente, para garantizar las mínimas condiciones de dignidad que debe tener cada persona, ordenando la reubicación de la familia en un término de 60 días. Por último, la Corte en la Sentencia T-199 del 2010 establece un pronunciamiento hito, que origina un cambio o giros dentro de las decisiones anteriores, logrando mediante una técnica legítima, como lo es el cambio jurisprudencial, proteger el derecho a la vivienda digna utilizando, las normas internacionales, haciendo hincapié en las observaciones emitidas por la CDESC (observación General $\mathrm{N}^{\circ} 4$, art. 8), órgano que ha sentado base en que el componente que constituye la habitabilidad de una vivienda adecuada que obliga al Estado a adoptar medidas de protección a las personas cuya vivienda ha sido afectada por la inestabilidad del terreno (zonas de alto riesgo).

Dentro del avance del proyecto de investigación que corresponde al estudio de los pronunciamientos que la Corte Constitucional ha proferido, respecto del derecho a la vivienda digna en las zonas de alto riesgo, se vislumbra que este derecho debió tener más desarrollo porque es la vivienda digna el derecho que le permite a la familia, como núcleo de la sociedad, tener un amparo real, un espacio de evolución de las personas por cuanto es la vivienda el lugar donde se produce la principal crianza de todos y cada uno de los colombianos. Una respuesta a esta problemática podría ser la siguiente: como el constituyente no quiso regular cada detalle de lo que constituye una vivienda digna, y prefirió dejar en el ESTADO una carga que no fue capaz de cumplir, el poder judicial, que en el caso bajo análisis encabeza la Corte Constitucional, conoció el problema y a través del diálogo y el juego democrático estableció las características particulares para cumplir esta directriz programática.

\section{REFERENCIAS BIBLIOGRÁFICAS}

Atienza, M. (2006). El derecho como argumentación. Barcelona: Ariel.

Atienza, M. (2010). Interpretación constitucional. Bogotá: Universidad Libre.

Atienza, M., \& Ruíz Manero, J. (1996). Las piezas del derecho. Barcelona: Ariel. 
Carbonell, M. (2005). Jurisdicción y argumentación en el estado constitucional de derecho. México D.F.: Universidad Nacional Autónoma de México.

Colombia - Corte Constitucional en Sentencia T-235 de 2011 (M.P. Luís Ernesto Vargas: Marzo 31 de 2011)

Colombia - Corte Constitucional. Sentencia C-010 de 2000 (M. P. Alejandro Martínez Caballero: Enero 19 de 2000)

Colombia - Corte Constitucional. Sentencia C-300 de 2011 (M. P. Jorge Iván Palacio Palacio: Abril 27 de 2011)

Colombia - Corte Constitucional. Sentencia C-849 de 2005 (M. P. Álvaro Tafur Galvis: Agosto 17 de 2005)

Colombia - Corte Constitucional. Sentencia T-021 de 1995 (M. P. Alejandro Martínez Caballero: Febrero 01 de 1995)

Colombia - Corte Constitucional. Sentencia T-1094 de 2002 (M. P. Manuel José Cepeda Espinosa: Diciembre 05 de 2002)

Colombia - Corte Constitucional. Sentencia T-1318 de 2005 (M. P. Humberto Antonio Sierra Porto: Diciembre 14 de 2005)

Colombia - Corte Constitucional. Sentencia T-1689 de 2000 (M. P. Alfredo Beltrán Sierra: Diciembre 07 de 2000)

Colombia - Corte Constitucional. Sentencia T-199 de 2010 (M. P. Humberto Antonio Sierra Porto: Marzo 23 de 2010)

Colombia - Corte Constitucional. Sentencia T-220 de 1994 (M. P. Eduardo Cifuentes Muñoz: Mayo 04 de 2000)

Colombia - Corte Constitucional. Sentencia T-258 de 1997 (M. P. Carlos Gaviria Díaz: Mayo 28 de 1997)

Colombia - Corte Constitucional. Sentencia T-495 de 2010 (M. P. Jorge Ignacio Pretelt Chaljub: Junio 16 de 2010)

Colombia - Corte Constitucional. Sentencia T-731 de 1998 (M. P. José Gregorio Hernández Galindo: Noviembre 27de 1998) 
Colombia - Corte Constitucional. Sentencia T-894 de 2005 (M. P. Jaime Araújo Renteria:Agosto 26 de 2005)

Colombia - Decreto Ley 919 de 1989 [con fuerza de ley]. Por el cual se organiza el Sistema Nacional para la Prevención y Atención de Desastres y se dictan otras disposiciones. Mayo 01 de 1989. D.O. N 38799.

Colombia - Ley 1523 de 2012. Por la cual se adopta la política nacional de gestión del riesgo de desastres y se establece el Sistema Nacional de Gestión del Riesgo de Desastres y se dictan otras disposiciones. Abril 24 de 2012. DO. $\mathrm{N}^{\circ} 48411$.

Colombia - Ley 388 de 1997. Por la cual se modifica la Ley 9 de 1989, y la Ley 2 de 1991 y se dictan otras disposiciones. Julio 18 de 1997, DO. N $^{\circ}$ 43091.

Colombia - Ley 715 de 2001. Por la cual se dictan normas orgánicas en materia de recursos y competencias de conformidad con los artículos 151, 288, 356 y 357 de la Constitución Política y se dictan otras disposiciones para organizar la prestación de los servicios de educación y salud, entre otros. Diciembre 21 de 2001. DO. N 44654.

Colombia - Ley $9^{\text {a }}$ de 1989. Por la cual se dictan normas sobre planes de desarrollo municipal, compraventa y expropiación de bienes y se dictan otras disposiciones. Enero 11 de 1989. DO. N 38850.

Hernández Becerra, A. (2008). Ordenamiento y desarreglo territorial de Colombia. Bogotá: Universidad Externado de Colombia.

López, J. D., Bateman, A. J., Vengoechea, J., \& López, J. M. (2009). La garantía de los derechos sociales. Bogotá: Universidad Pontificia Javeriana.

Pisarello, G. (2007). Los derechos sociales y sus garantías. Madrid: Trotta.

Robledo, P. (2010). El derecho a una vivienda digna en el marco de las competencias municipales de ordenación del territorio. Derecho del Estado. No. 24, 24.

Ruíz Manero, J. (2005). Principios, objetivos y derechos. Otra vuelta de tuerca. Doxa, Cuadernos de filosofía del Derecho 28, 28. 
Santofimio, J. O. (2007). Tratado de derecho administrativo (Vol. II). Bogotá: Universidad Externado de Colombia. 